\title{
Community-University Partnerships
}

Using Participatory Action Learning and Action Research (PALAR)

Judith Kearney

Griffith University

Lesley Wood

Community-based Educational

Research (COMBER),

North-West University

\section{Ortrun Zuber-}

Skerritt

Griffith University and

Tshwane University of Technology
Gateways: International Journal of Community Research and Engagement Vol 6 (2013): 113-30

(C) UTSePress and the authors

ISSN 1836-3393
As a core function of a university, community engagement needs to be embraced by all academics in higher education, enabling research for, and as, social change. This article considers participatory action learning and action research (PALAR) as an approach for community-university partnerships to foster and maximise the rewards of university engagement with communities for collaborative research and problem-solving. It has the following dual focus: (1) to explain how PALAR can provide opportunities for universities to work collaboratively with community members; and (2) to demonstrate what can be achieved using PALAR.

The three R's of PALAR - relationships, reflection and recognition - are the key elements that promote a truly participatory approach to knowledge creation and practical social and educational improvements. In addition, PALAR is a useful method for disrupting traditional perspectives of communityuniversity relationships and interaction.

PALAR has the potential to: (1) promote mutual learning and development; (2) foster the cascading of learning and knowledge to others in the community; and (3) co-create knowledge that is relevant, contextualised and useful, both for meeting community needs and producing research output as required of universities.

Two case studies (one South African and one Australian) will provide evidence of the usefulness of PALAR in developing the capacity among participants (academic researchers, postgraduate students and community members) to collaborate for meaningful educational and social change. To provide a context for these case studies, the following section briefly explains the concepts of action learning (AL), action research (AR), participatory action research (PAR), and participatory action learning and action research (PALAR) (based on Zuber-Skerritt 2011). A model is presented for the design of community development programs through university-community partnerships using PALAR. 


\section{CONCEPTUAL FRAMEWORK FOR PARTICIPATORY ACTION LEARNING AND ACTION RESEARCH (PALAR)}

\section{Action Learning and Action Research (ALAR)}

Many theories and definitions of action learning (AL) and action research (AR) have been developed independently of each other over the last few decades. The two concepts were united in the First World Congress on Action Learning, Action Research and Process Management (ALARPM - later renamed ALARA) held in Brisbane in 1990, and have since been integrated conceptually as ALAR (Zuber-Skerritt 2009). In brief:

'Action Learning' means learning from and through action or concrete experience, as well as taking action as a result of this learning. Similarly, 'Action Research' is a cyclical iterative process of action and reflection on and in action. Through the careful thought of collaborative reflection we conceptualize and generalize what happened (action). We can then investigate (research) whether our conceptions hold ground in new situations; that is, we try to find confirming and disconfirming evidence to inform our assessment and further reflection. The main difference between 'Action Learning' (AL) and 'Action Research' (AR) is the same as that between learning and research generally. Both include active learning, searching, problem solving and systematic enquiry. However, Action Research is more systematic, rigorous, scrutinizable, verifiable, and always made public (in oral or published written/electronic forms) (p. 6).

\section{Participatory Action Research (PAR)}

As the name suggests, PAR involves the participants in all or most phases and processes of the research (design, implementation/ action and evaluation) as equal partners. PAR as a concept and practice was originally developed for community engagement in developing countries by pioneers such as Paulo Freire $(1972,2004)$ and Orlando Fals Borda (1998; Fals Borda \& Rahman 1991) in Latin America; Md Anisur Rahman (2008) and his associates in Pakistan and Bangladesh; and Marja-Lisa Swantz (2008) and her colleagues (Swantz, Ndedya \& Masaiganah 2001) in Tanzania. Although these researchers are university trained, they were able to reach beyond formal education to support people who were disadvantaged, oppressed and believed themselves to be powerless. They collaborated with community-based organisations, nongovernment organisations (NGOs) and others in civil society, with funding from private and public sectors including the World Bank.

Meanwhile, PAR has become an international network (based at Cornell University: cornell.par.network@gmail.com) which collaborates with other similar networks and associations such as the international Action Learning and Action Research Association (based in Australia: www.alara.net.au) and the Collaborative Action Research Network (based in the UK: http:// www.esri.mmu.ac.uk/carnnew/). 


\section{Participatory Action Learning and Action Research (PALAR)} The concept of PALAR integrates ALAR and PAR in a holistic way. People involved in PALAR projects are interested in participating (P) and working together on a complex issue (or issues) affecting their lives, learning from their experience and from one another (AL) and engaging in a systematic inquiry (AR) into how to address and resolve this issue/issues.

Traditionally, a researcher has been defined as an expert, external, distant observer who uses certain variables, research methods - predominantly quantitative methods and statistics - and large samples of 'subjects' to establish 'objective truth'. In the PALAR paradigm, the researcher joins the 'tribe' - as in anthropology - and facilitates the whole process of research and development with 'participants' as co-researchers in all phases of the research. Instead of large numbers of subjects on whom the researcher conducts their research 'objectively' to achieve validity and reliability, PALAR focuses on small numbers of people in a community who are engaged in addressing an important, complex problem collaboratively and actively because they are directly affected by the problem and its solution. Research methods used in PALAR projects are predominantly qualitative, rather than quantitative as in traditional research. The base primary criterion for quality and reliability is 'authenticity'. This means that research results are valid if they are authentic, i.e. recognisable and confirmed in terms of mutual benefits, by the participants in the research.

Outcomes of PALAR include individual participants acquiring problem-solving, communication and lifelong learning skills, self-confidence and transformational change at the personal, professional and community/organisational levels through reflection on action/practice. PALAR outcomes also include a published contribution to knowledge in practice and theory.

PALAR integrates what we identify as the three main areas of development: (1) community development; (2) leadership development; and (3) the development of lifelong learning. These three separate areas of concern are integrated through PALAR as a positive and essential approach to community engagement.

\section{A generic model of PALAR programs}

Figure 1 presents the eight main components or phases of a structured action learning program that includes collaborative PALAR team projects as a methodology for addressing a major issue or concern in a community or organisation. This model is a general guide, with flexibility in choice and use of process and methods in each phase of the model. It has proven to be effective in designing PALAR programs/projects in higher education, management education, and community and organisational development in several countries (Zuber-Skerritt 2011). 
Figure 1: A generic model for PALAR programs (Zuber-Skerritt 2002, p. 144)

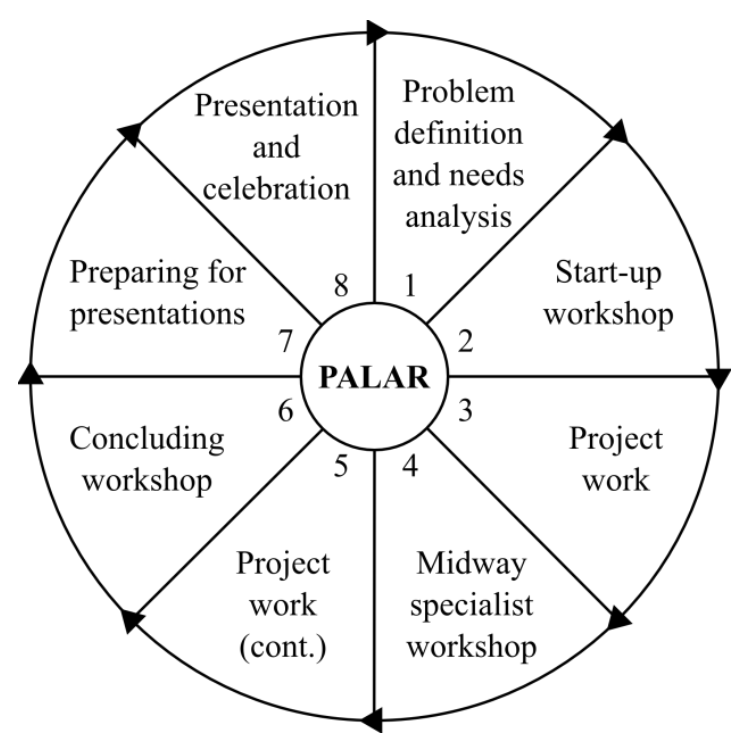

1 Problem definition and needs analysis. The first phase of PALAR is to facilitate a needs analysis in which the participants brainstorm to clearly identify the main problems or issues that need to be addressed urgently in the community. They then prioritise the issues and establish work-based project topics and teams to design the program and prepare the background materials and resources.

2 Start-up workshop. The purpose of a start-up workshop preferably residential to keep participants away from the distractions of the workplace and family commitments - is to: (1) create a supportive environment conducive to relationshipbuilding, trust, open discussion, reflection and learning; and (2) lay the foundations for participants to acquire, create and cascade relevant knowledge and skills related to PALAR for the design, management and evaluation of their projects. The workshop of one to five days' duration, depending on the scope of the problem/s and issues that participants will work on in their projects, will include the following key areas:

— vision-building and team-building

- introduction to PALAR

- project design, management and evaluation

- qualitative research methods

- using information technology, library resources, electronic databases, and bibliographic packages such as 'Endnote'

- the project planning process, with an emphasis on context analysis.

3 Project work. In this third phase, participants attend regular team meetings (without the project leader/s but supported by a mentor as necessary), to work on their particular topic and research project (including data collection, analysis, feedback to their co-participants and collaborative interpretation of results). All teams also meet once a month to discuss progress and any problems.

4 Mid-way specialist workshop. It might be necessary to conduct a mid-way workshop with all teams attending to provide 
specialist input in certain skill areas as needed and identified by participants (for example, library or IT skills), allowing them to continue working independently in their teams.

5 Project work continued. By this stage, team members have developed the necessary skills and confidence to operate as autonomous learners and researchers. They meet regularly with their teams and monthly with all the other teams to present their progress reports, exchange their ideas and experiences and ask questions.

6 Concluding workshop, presentations and celebration. The purpose of the concluding workshop is for participants to finalise project results. It provides a valuable opportunity for them to reflect on the successes and failures of their PALAR efforts, the significance and impact of their work, and whether/how it might be possible and useful to continue the PALAR project.

It is important to help participants prepare: (1) their oral presentations (usually 10-15 minutes per team) to all stakeholders (the media, colleagues, family, friends and the wider community); and (2) their written reports (newsletters, journal articles or book chapters) or audio-visual presentations. Help can also be provided in organising the big finale: the presentation and celebration day. This is the highlight of any PALAR program, often involving the presentation of certificates or other awards followed by dinner, music, dance and songs. Participants feel recognised and rewarded for their completed work, synergy and team spirit. It is an opportunity for them to express pride in their achievements and their contribution to positive change in the community and to the betterment of their own and other people's lives.

The following two case studies exemplify the usefulness of PALAR as a means by which university academics can engage with communities in partnerships. The first case study examines how PALAR's 3Rs - relationship, critical reflection and recognition are essential to the methodology. The second case study highlights what can be achieved by outlining processes and outcomes that evidence the development and sharing of personal and group learning and the co-creation of knowledge.

\section{PARTICIPATORY ACTION LEARNING AND ACTION RESEARCH (PALAR) IN HIGHER EDUCATION - A CASE STUDY IN SOUTH AFRICA}

\section{The Context of Research in South Africa}

This case study reports on a fledgling community-university partnership in South Africa. Through PALAR, the partnership aims at developing academics' capacity to engage with community members in development projects to address local concerns sustainably, while also fulfilling their research obligations. Designed as a capacity development program comprising four discrete projects, the partnership uses the PALAR process model described earlier (see Figure 1). This program is in its beginning 
stages and is challenging the dominant paradigm of research for community development in South Africa. So the focus here is on how far the paradigm and methodology of PALAR can help shift the mindsets of academics, postgraduate students and community members in South Africa concerning the aims, process and outcomes of what is construed as research.

Community engagement has quite recently been introduced as a core area against which universities and academics are evaluated in South Africa (Council for Higher Education 2010). Most South African universities acknowledge their main function is to generate knowledge that contributes to theory and to innovations that will, in turn, lead to sustained societal improvement. Some of the common values they uphold which inform and define their institutional ethos and distinctive educational purpose and philosophy are: (1) respect for diversity and for the natural environment, excellence and integrity; and (2) Ubuntu, a traditional African concept characterised by human interdependence and open, friendly, supportive relationships. These values are very much consistent with three R's of PALAR: relationships, reflection and recognition.

The authors of this article therefore decided to provide tertiary-level researchers and postgraduate students with an opportunity to learn how to conduct community engagement for positive social change, researching with, rather than on, community members, while perceiving them as co-participants rather than mere informants and/or recipients of knowledge. Funded by the Australian foreign aid program, AusAID, we presented an intensive, residential five-day workshop on PALAR (based on the model in Figure 1 and summarised in Table 1).

\section{Key Elements and Observations}

\section{The research question}

The research question that guided this project was: How can PALAR be useful for building the capacity of academic researchers and community members to partner in research to bring about improvement in education and in society at large? Participants from the Faculty of Education at two South African universities formed four teams, each team consisting of a faculty member, a postgraduate student and a community representative. The teams already had a topic in mind when they attended the workshop, so they could apply their learning to a real situation.

\section{Methodology}

Data on the participants' experiences of PALAR were collected during and after the workshop by means of participants' written reflections, their reports on how they cascaded their learning in their respective communities, and the transcribed recordings of subsequent monthly meetings of their action learning sets. These data were analysed thematically (Creswell 2005) using the research question as a theoretical lens. The study was designed to comply with the quality criteria to enhance trustworthiness summarised by Shenton (2004) which enhance credibility, 
dependability, transferability and confirmability of the data. The study also complied with the usual ethics procedures of informed consent, voluntary participation and confidentiality (Bogdan \& Biklen 2007). Table 1 presents a brief summary of the content (aims and activities) of the PALAR program and of individual team projects.

\begin{tabular}{|c|c|c|c|}
\hline $\begin{array}{l}\text { Aims of } \\
\text { program }\end{array}$ & $\begin{array}{l}\text { 1. Build capacity in } \\
\text { researchers at tertiary } \\
\text { level using PALAR }\end{array}$ & $\begin{array}{l}\text { 2. Design four research } \\
\text { projects using PALAR to } \\
\text { engage with communities }\end{array}$ & $\begin{array}{l}\text { 3. Subsequent cascading of learning at } \\
\text { university and in the community }\end{array}$ \\
\hline
\end{tabular}

Individual How can youth be involved most effectively in designing and implementing peer education projects programs for preventing teen pregnancy?

How can alumni be involved most effectively in school improvement?

How can the potential of non-music specialist Grade R practitioners be unlocked most effectively to nurture the musical development of learners?

How can community be involved most effectively in setting up and running a new school?

\begin{tabular}{llll}
\hline $\begin{array}{l}\text { Workshop focus } \\
\text { (5 days) }\end{array}$ & $\begin{array}{l}\text { Principles and processes of } \\
\text { PALAR }\end{array}$ & $\begin{array}{l}\text { Strategies for designing and } \\
\text { supervising PALAR projects }\end{array}$ & $\begin{array}{l}\text { Writing and publishing the results of } \\
\text { Ongoing }\end{array}$ \\
$\begin{array}{llll}\text { Monthly meetings of } \\
\text { development }\end{array}$ & Progress reports on projects & Reflections on personal learning and \\
& action learning sets & & community change
\end{tabular}

\begin{tabular}{llll}
\hline $\begin{array}{l}\text { Ongoing } \\
\text { cascading of } \\
\text { learning }\end{array}$ & $\begin{array}{l}\text { Via formal workshops at } \\
\text { the two universities }\end{array}$ & $\begin{array}{l}\text { Via formal cascading } \\
\text { events in communities }\end{array}$ & $\begin{array}{l}\text { Via informal cascading in everyday } \\
\text { community interactions }\end{array}$ \\
$\begin{array}{l}\text { Finalising } \\
\text { results }\end{array}$ & Concluding workshop & $\begin{array}{l}\text { Preparing for oral and } \\
\text { written reports }\end{array}$ & Presentation and celebration day \\
\hline
\end{tabular}

Table 1: Summary of aims, projects and program content

\section{Observations}

Since this project is still in progress and the results have not yet been finalised, we present a few key observations made over the first eight months of the project using the three R's of PALAR (relationship, reflection and recognition) as an analytic lens. Direct quotes are from participants.

PALAR results in a high degree of personal growth through the process of reflection. The PALAR process requires the researcher to reflect critically on their thinking, feelings and actions. This results in participants perceiving personal growth and learning as an integral part of the process. The project supervisors who arrived as confident, seasoned researchers, suddenly found themselves in new terrain where their past assumptions were being challenged. Their reflections revealed that although they welcomed this learning, it was at times difficult for them to make the shift to a more democratic way of supervising and researching. The initial project outlines and reports frequently indicated an instinctive tendency to revert to familiar, more traditional methodology and discourse. The postgraduate students also found it difficult to unlearn what they had been taught in previous research courses at university. 
One doctoral candidate, for example, continually referred to herself as 'the researcher', rather than using the first person as is appropriate in the narrative account of the PALAR process. However, because of the trusting relationship between participants in the learning set - trust that had developed quickly through several aspects of the workshop - they felt comfortable helping each other and pointing out instances where they were deviating from PALAR principles and processes. While participants offered numerous accounts of facing their own lack of knowledge during cascading sessions, this acted as a motivator to identify further learning needs and take responsibility for meeting those needs. Action learning was identified as a main factor in this process, enhanced by participants' dialectic reflection (Winter 1987) within the action learning set.

The relationship aspect of PALAR changes the way participants think and feel about research. As one participant put it, 'PALAR has provided me with a way of making my engagement with community human'. This comment led us to believe that the main attraction of PALAR for many of the participants is that 'research has now been made easy and interesting', largely because PALAR requires the formation of democratic, egalitarian relationships that recognise the potential of community members as co-researchers. The action learning set participants no longer felt like they were intruding on the community, but that they were a part of it, working together towards mutual improvement. One participant claimed he found great satisfaction when working with the community members and witnessing them 'discovering the "intellectual" in themselves and the work they are doing'. This was especially gratifying since the members of this community, having experienced a low level of formal education, tended to regard themselves, and be labelled by others, as 'illiterate'. After working with project participants and becoming participants themselves, they perceive that they are actually contributing to research on how to start up a community school - and thus feel recognised and valued.

However, some of the project participants at times found it difficult to form trusting, democratic relationships with the community. One doctoral student struggled to involve the teachers working in the school in her project and concluded that 'perhaps this methodology is not for me'. When she shared this experience with the action learning set, another participant with deep insight into the thinking of this particular community helped her see what she might do differently to make the community members feel more valued and part of the project. Through action learning and critical reflection, this 'negative' experience was turned into valuable learning for her and the other participants. The action learning set experience helped participants to understand that participation cannot be just empty rhetoric: engagement has to have real value for the community and their contribution as coresearchers needs to be recognised as valuable. 
The focus on relationships allows 'a vibrant community of practice to emerge'. The monthly action learning set meetings were supplemented by e-mail contact, enabling participants to share the latest articles on action research or other topics that the teams were researching. Participants' feedback was very positive. Members of the group also asked each other for help in accessing suitable literature and theories for their individual projects. However, it was difficult to draw all the members together in one place, even once per month.

Participants' normal work at university and school continued and at each meeting at least two people sent apologies for their absence. As project leader, I was sometimes downhearted about this, taking it as a sign of low commitment to the project. Nevertheless, it taught me and the project facilitators to keep focussing on the positive and continue motivating, rather than castigating members for their absence. We understand that relationship must take precedence over a task orientation in the early stages of the PALAR process. The participants perceived the ongoing interaction as beneficial, as comments such as these indicate: 'it was good and exciting to experience the learning that emerged as a result of the group interaction' and 'group interaction has made me realise we are all human'. This points to an increased capacity to embrace diverse opinions and experiences through the relationships developed within the action learning set.

A high level of motivation and enthusiasm was created through relationships. It was really gratifying to experience the sometimes overwhelming feeling of motivation and enthusiasm with which the participants cascaded their learning. During the few weeks following the start-up workshop, they reported many instances of informal cascading as they shared their knowledge in all types of contexts - with church committees, with parents/staff/volunteers at school, with community organisations, one-on-one with colleagues and fellow students, and even with their families. The democratic approach to identifying needs and finding ways to meet them resonated in all aspects of their lives. One participant, who is a doctoral candidate and a teacher, shared how there was a much more collegial climate at her school since she had introduced PALAR strategies in staff meetings and projects, suggesting that the relationship element of PALAR was responsible. Another postgraduate student, who is a school principal, has changed the whole style of management and administration at his school in accordance with PALAR processes and enthused about the energy and commitment it was creating among his staff as they worked together towards a common goal. There were many accounts of how 'PALAR has become a way of life' for participants.

\section{The Challenges - Letting go and Opening up}

Making the shift from a traditional, researcher-dominant mode of enquiry to PALAR is not always easy. As tertiary-level researchers, we are used to determining the 'what, where and how' of the process, necessarily tailored to suit academic proposal and report 
requirements and time allowed for completion of the study. PALAR requires letting go of this control and trusting in the participatory process. This is easy to say in theory, but not so easy to do in practice - a view many of the participants in this project shared. It was easier for those who were already part of the community - in this case, the postgraduate students who were teachers at the school/community with whom they were researching. They seemed to be more in tune with community thinking and ways of working and had a clearer idea of how to interact with community members than did their university supervisors who were not used to ceding control of the process.

Supervisors reflected on how they had to learn to trust the judgement of their postgraduate students and rely on their knowledge of the community as a basis for making strategic decisions about the research process. The supervisors found this difficult, but the honesty with which they shared their responses to this new research process with the group helped to open up critical discussion on this issue. Supervisors thus learnt from their students, making for a more democratic supervisory relationship in line with PALAR egalitarian values.

Another challenge for academic participants was how to communicate with communities, whose members in most cases are not familiar with the discourse used by academic researchers. Good communication is the basis for forming trusting relationships and so it is a vital aspect of the PALAR process.

Surprisingly, since academics are used to writing reports, it became extremely difficult to get the academic project participants to actually write their in-depth reflections on a regular basis. Most gave lack of time as the reason, but we suspect that many found it challenging, perhaps personally confronting, particularly as all reflections were posted on Dropbox and could be accessed by all group members (we wanted all data to be communally owned and used). This finding needs to be explored in view of the supervisors' tendency to uphold traditional, hierarchical relationships between supervisor and student and their role as 'experts' - an attitude which may deter them from openly criticising their past practices in light of new understanding as well as discussing their own current learning needs. The community members in the team, some of whom are postgraduate students being supervised by the academics, do not appear to have this problem. Perhaps because of their community allegiance they do not primarily identify as participants in the traditional academic relationship and therefore feel less vulnerable to the disempowerment it sets up. These speculations will be followed up in future action learning set meetings.

While the passion and excitement displayed by the participants using PALAR in their research projects cannot be captured in words, their submission of over 20 reports of cascading to colleagues and students at the university and in the various project communities in just seven months is a measure of their enthusiasm. We are able to see how PALAR's three R's relationship, critical reflection and recognition - actually work in 
practice as a truly participatory approach to creating knowledge and practical improvement in the social and educational circumstances of a disadvantaged community in an economically developed country.

\section{PARTICIPATORY ACTION LEARNING AND ACTION RESEARCH (PALAR) IN HIGHER EDUCATION - AN AUSTRALIAN CASE STUDY}

\section{Logan City - the Research Context}

The setting for this partnership was Logan City in the BrisbaneGold Coast corridor in Southeast Queensland, one of 10 areas across Australia identified by the federal government as experiencing entrenched disadvantage and long-term unemployment (Department of Education, Employment and Workplace Relations nd). In some Logan suburbs, such as Woodridge and Kingston, the unemployment rate in 2012 exceeded 19 per cent whereas Queensland's average rate was 5.5 per cent (Department of Education, Employment and Workplace Relations 2012). However, against this backdrop of disadvantage, Logan City proudly boasts that it is one of Queensland's most culturally diverse cities, with more than 27 per cent of people from countries where English is not the first language (Logan City Council 2012). The city is a major settlement location for refugee families and is a designated high-growth area. With a rapidly increasing representation of people from the Pacific Island regions, predominantly of Samoan heritage, Samoan is the most commonly spoken language other than English. However, while Samoan families are strongly represented in local schools, they are underrepresented in higher education.

Several factors explain this under-representation. One is non-alignment between home and school. Understandings and expectations about children's roles, responsibilities and communication practices contrast markedly between parents educated in Samoa and Queensland teachers (Kearney, Fletcher \& Dobrenov-Major 2011). This non-alignment has inhibited strong school-home partnerships and has constrained families' understanding of pathways into higher education and the longterm benefits of undertaking university studies. This situation is exacerbated by Australian government policy. Since 2001, most Samoan family members have entered Australia as New Zealand citizens on non-protected Special Category Visas, so they are able to live and work in Australia but are not entitled to many benefits associated with Australian citizenship. For example, this visa status makes their children ineligible for Australian government higher education support such as HECS-HELP, the Higher Education Contribution Scheme for Australian citizens. For most Samoan families, the up-front payment of fees is prohibitive so high school leavers are denied higher-education opportunities.

The partnership described in this case study is between a university campus in Logan City and a Samoan community 
organisation called the Voice of Samoan People (VOSP). The partnership, which has continued since 2010, was established between VOSP and the university to mutually address Samoan under-representation in higher education in Logan. Aspects of this partnership will be discussed to illustrate the processes of PALAR, with emphasis on PALAR's potential to: (1) promote mutual learning and development; (2) foster the cascading of learning and knowledge to others; and (3) co-create knowledge that is relevant, contextualised and benefits the common good.

Promoting Mutual Learning and Development through PALAR Members of VOSP, a community organisation, were uncertain how to address the challenges many Samoan families experience in their new lives resettling in Logan. The university community shared this uncertainty. However, the potential partnership between the university and VOSP sealed a common interest in responding together to these concerns, reaffirming that the university and its staff, like VOSP, are part of the Logan community. Our shared interest developed into shared optimism. Through our knowledge, ideas, networks and energies - our shared action through PALAR - we believed we could make a difference. At the inaugural meeting of the partnership we brought together 20 people associated with the university or VOSP. The cultural understandings and life experiences of these participants were very diverse, but we all shared a will to create positive change in the community.

\section{The focal question}

First we negotiated a focal question for our group members' responses: For you personally, what are the felt needs of the Samoan community to improve educational opportunities for all? Using the Nominal Group Technique - a structured, group decision-making process enabling all participants to contribute equally in response to a question - the group identified the following set of needs for the Samoan community:

-increased parental involvement in children's learning

-improved communication amongst immediate stakeholders, e.g. parents, teachers and school children

-stronger sense of belonging for children and youth within the Samoan culture and the wider community in Logan, e.g. at school, home, church and university

- more confident use of both Samoan and English.

Having completed the needs analysis, we agreed on four project teams, with each addressing one or more of the identified needs. Participants at the inaugural meeting identified an interest in particular projects and agreed to meet again to develop project plans. In general, we followed the phases of PALAR programs shown in Figure 1. However, a recommended residential startup workshop was not possible for participants because of family commitments and financial constraints that prevented them from taking time off work. Instead, we met regularly in the evening after work. At our second meeting we started with a relationship- 
building exercise to encourage openness and mutual respect. This involved sharing significant turning points in our lives with two other participants whom we knew least. From that moment on, our collective identity strengthened. Trust developed quickly and we began to speak openly with each other as a group about processes that were culturally appropriate for all participants. These included issues such as managing time, the importance of prayer at the beginning and close of meetings, and protocols relating to hospitality. At that second meeting we also completed a visionbuilding exercise. This enabled project teams to envision possible outcomes and to share them in pictorial form with the wider group. It was at this point that we started to speak confidently about actioning positive change.

Subsequent meetings involved learning about the PALAR process and progressing project work. Each team conducted a context analysis that involved discussion with stakeholders, a SWOT (strengths, weaknesses, opportunities, threats) analysis, careful consideration of constraints, and compilation of a resource inventory. Teams regularly revisited their vision statement and the broader outcomes from the initial needs analysis. This was especially important before developing action plans for the four projects. Individual teams met in their action learning sets and with all other teams as a wider group to share progress and to discuss challenges. Project work generated considerable interest beyond the original participants, with the number of Samoan participants increasing at each meeting.

\section{Cascading learning and knowledge to others}

One of the four project teams focused on promoting Samoanheritage youth's sense of belonging within their traditional culture. This was seen as important since many of these young people struggle with competing demands resulting from tension between their parents' island traditions and their own participation within contemporary Australian society (Kearney \& VOSP 2011). Ravulo (2009) suggests that inability to resolve these demands inhibits development of a well-defined identity which underpins pro-social behaviors. This project team, which included four chiefs, interviewed Samoan-heritage youths to identify what they wanted to know and better understand to live more comfortably in their community. Samoan members of the team developed this information and made it available on a website while university staff and students contributed technological expertise. This project work has resulted in invitations to the project team to speak with teachers about Samoan cultural beliefs and practices, and a request from a government agency for a report on Samoan cultural traditions.

A second project team worked with students from local secondary schools using creative engagement strategies to provide the young people with a voice to speak openly about, and find ways to address, issues important to them. A series of workshops was held to unlock talent, raise aspirations and promote action 
leadership among participants and beyond. This was the beginning of a more formal approach to youth leadership now funded by the university.

A third project focused on families. The team who surveyed Samoan-heritage teenagers and parents found that many young people lacked confidence in expressing their point of view clearly to parents and teachers. Parents realised that improved communication with their children was a priority. A series of workshops was held in local church congregations. These inspired the development of a Samoan parenting program, delivered in Samoan language, as an ongoing partnership between the university and local churches.

The fourth project was operationalised in the context of a local primary school where more than half the students are of Samoan heritage. Much of the work focused on developing the role of a Pacific Island Liaison Officer (PILO) within the school. The project team started with a workshop to negotiate the role with teachers so that there was clear understanding of how the role could work. A parents' night was held with information conveyed in both Samoan and English. This attracted about 60 parents whereas previously, when the event was promoted through a notice in the school newsletter, very few had attended these events. We learnt that parents respond to personal, spoken invitations and regard the parents' night as important when church leaders and community elders endorse the event. A study centre and a Samoan-language class were established with classes offered after school to all students. Both initiatives were supported by Samoan parent volunteers. Since the project started, rates of absenteeism and incidents of late arrival at school have been reduced. Behaviour issues have lessened and teachers are more confident about managing these issues in a more culturally responsive way. The school is currently trialling a teaching role that encourages teachers and Samoan parents to work collaboratively to improve the oracy of children in the early years of formal schooling.

Outcomes of all projects were acknowledged and celebrated at a special community event at the university. Samoan community members took a lead role in the celebration, which attracted strong attendance from among their families and friends and publicly reaffirmed the partnership between the community and the university. As a result of these very visible and positive outcomes, the university appointed a full-time Project Officer to work collaboratively with communities to sustain outcomes and develop further initiatives to raise aspirations and educational attainment. The university has extended this role for another year and project work continues in a strong collaboration with local schools and the wider community. Enrolment of Samoan students at the university continues to increase and a special Pacific Island graduation, hosted by the university, is now an annual event and attended by hundreds of community members. 


\section{Co-creating knowledge}

Overall, PALAR enabled us to engage collaboratively and constructively with complex community issues, working with and co-creating local knowledge and processes towards achieving sustainable solutions that serve shared community and university interests. Some particular outcomes of using PALAR in partnership with VOSP are especially pleasing. Some Samoan members of project teams are now themselves undertaking university studies - an aim which motivated VOSP to initiate contact with the university in the first place. Another is the collaborative writing of reports and articles - an unexpected positive outcome which averted the all too common situation where traditional Western research paradigms disregard the voices and protocols of the community under enquiry (Smith 1999). PALAR also encourages practices such as reciprocity and mutual respect that align with Samoan cultural traditions and are integral to a Talanoa approach, which is a conversational method advocated by Pacific Island researchers (Vaioleti 2006).

PALAR works as a means to help community members better understand and reorient the entrenched power structures in society that work to disempower newcomers like the Samoanheritage peoples who may lack familiarity with cultural norms and institutional processes. These shortcomings are intrinsic to sustaining the power relationships in which newcomers see themselves as disempowered citizens. PALAR is about personal and community empowerment.

\section{Challenges - Understanding Norms and Protocols}

Our PALAR project was not without challenges. Perhaps the main challenge for our partnership related to diversity within the participant cohort. The life experience, cultural conditioning and worldviews of Samoan community members and university academics were clearly different, and both sides of the partnership were largely unfamiliar with each other's worlds. This resulted in misunderstandings. For example, non-Samoans sometimes overlooked what are norms in Samoan society, such as the importance of prayer to start and end public meetings and protocols relating to food and hospitality procedures. We mispronounced names. Fortunately, these incidents were met with good humour and a willingness to learn more about each other's cultures. True to PALAR principles, as co-participants we worked together with mutual trust and respect.

Ironically, while diversity within the group led to challenges, it also enriched our partnership, strengthened our resolve to work together towards our shared goals, and was a valuable, empirical source of learning for us all. Indeed, it is in working through the challenges of research that we learn more about the problems that we seek to resolve, how to resolve them in practice, and by extension, through reflection and meta-reflection (Fletcher \& Zuber-Skerritt 2008), what this means for PALAR as methodology in theory and practice. Complementary to our shared will, the combination of participants' diverse endowments of knowledge, 
skills and networks was intrinsic to the partnership's success. In all, PALAR's flexibility, adaptability, and equalising of us as coparticipants made it a particularly effective methodology for this complex, people-centred research project.

\section{CONCLUSION}

This article has addressed the focal question of how to use the process and methods of PALAR most effectively to promote university engagement with the community through partnership for the benefit of all participants as well as their universities and communities at large. It has provided: (1) a conceptual framework for PALAR in the context of community engagement; and (2) a model for designing PALAR programs/projects (see Figure 1). The two case studies - one based in South Africa and the other in Australia - illustrate how the conceptual framework and the design/process model may be applied to effect positive educational and social change in communities through partnership with a university. The case studies also highlight challenges for practice that will need further research.

As the case studies illustrate, the essential features of the PALAR process are the three R's: relationships, reflection and recognition.

Relationships and relationship-building, which underpin the development of trust and the team-building process, is intrinsic to the project's ongoing success and sustainability and to the passage of learning.

Reflection is an essential practice for all members of project teams as they implement and further develop action plans that align with the initial needs analysis. The iterative process of reflection enables project participants to: (1) learn more about their communities, about themselves and about the knowledge they have co-created; and (2) identify requirements for further action. Working together with project participants in these case studies, we created new ways of knowing, understanding, doing and feeling as a result of our PALAR experience.

Recognition of outcomes in the PALAR process - of both action and learning - is important as an affirmation of collective and personal achievements and must be celebrated as such. Recognition and celebration are usually not the final step in the research and learning process, but rather the next step in a new cycle of the PALAR process that engages communities - in partnership with universities - in sustainable, community-centred development.

\section{REFERENCES}

Bogdan, RC \& Biklen, SK 2007, Qualitative research for education: An introduction to theories and methods, 5th edn, Pearson Education, Boston.

Creswell, J 2005, Educational research: planning, conducting and evaluating qualitative and quantitative research, 2nd edn, Merrill/Pearson Education Upper Saddle River, New Jersey. 
Department of Education, Employment and Workplace Relations (DEEWR) 2012, Small Area Labour Markets Australia, March Quarter, Commonwealth of Australia, Canberra, viewed 18 November 2012, http://www.deewr.gov. au/Employment/LMI/Documents/SALM Mar2012.pdf

Department of Education, Employment and Workplace Relations (DEEWR) nd, Building Australia's future workforce: Place-based initiatives, DEEWR, Canberra, viewed 12 November 2012, http://www.deewr.gov.au/ Department/Budget/Documents/20112012/Place-Based Initiatives.pdf

Fals Borda, O 1998, People's participation: Challenges ahead, Tercer Mundo Editores, Bogota.

Fals Borda, O \& Rahman, MA 1991, Action and knowledge: Breaking the monopoly with participatory action research, Apex Press, New York.

Fletcher, M \& Zuber-Skerritt, O 2008, 'Professional development through action research: Case studies in South African higher education', Systemic Practice and Action Research, vol. 21, pp. 73-96.

Freire, P 1972, Pedagogy of the oppressed, Penguin, Harmondsworth, UK.

Freire, P 2004, Pedagogy of indignation, Paradigm, Boulder.

Kearney, J \& VOSP 2011, Samoan cultural beliefs and practices. A Report for Child Safety Services, School of Education and Professional Studies, Griffith University, Brisbane.

Kearney, J, Fletcher, M \& Dobrenov-Major, M 2011, 'Non-aligned worlds of home and school: A case study of second-generation Samoan children', Journal of Family Studies, vol. 17, pp. 146-56.

Logan City Council 2012, Community profile: Logan Central, viewed 12 November 2012, http://profile.id.com.au/logan/birthplace?WebID=290

Rahman, MA 2008, 'Some trends in the praxis of participatory action research', in P Reason \& H Bradbury (eds), The Sage handbook of action research: Participative inquiry and practice, Sage, London, pp. 49-62.

Ravulo, J 2009, The development of antisocial behaviour in Pacific youth, Doctoral dissertation, University of Western Sydney, viewed 14 November 2012, http://arrow.uws.edu.au:8080/vital/access/manager/Repository/uws $: 8264$ ?fO=type $\% 3 \mathrm{~A} \% 22$ THESIS $\% 22$

Shenton, AK 2004, 'Strategies for ensuring trustworthiness in qualitative research projects', Education for Information, vol. 22, pp. 63-75.

Smith, LT 1999, Decolonizing methodologies: Research and indigenous people, University of Otago Press, Dunedin, NZ.

Swantz, ML 2008, 'Participatory action research as practice', in P Reason \& H Bradbury (eds), The Sage handbook of action research: Participatory inquiry and practice, Sage, London, pp. 30-48.

Swantz, ML, Ndedya, E \& Masaiganah, MS 2001, 'Participatory action research in southern Tanzania with special reference to women', in P Reason \& H Bradbury (eds), The Sage handbook of action research: Participative inquiry and practice, Sage, London, pp. 386-95.

Vaioleti, TM 2006, 'Talanoa research methodology: A developing position on Pacific research', Waikato Journal of Education, vol. 12, pp. 21-32.

Winter, R 1987, Action-research and the nature of social inquiry: Professional innovation and education work, Gower Publishing Company, England. 
Zuber-Skerritt, O 2002, 'A model for designing action learning and action research programs', The Learning Organization, vol. 9, no. 4, pp. 143-49.

Zuber-Skerritt, O 2009, Action learning and action research: Songlines through interviews, Sense Publishers, Rotterdam.

Zuber-Skerritt, O 2011, Action leadership: Towards a participatory paradigm, Springer International, Dordrecht. 